\title{
Produção Científica na Área da Surdez: Análise dos Artigos Publicados na ReVista Brasileira de EducaÇáo Especial no Período de 1992 A 2013 $^{1}$
}

Scientific Production in the Area of DeAfNess: Analysis of ARticles Published in BRAZILIAN JoURNAL of SPECIAL EDUCATION FROM 1992 to 2013

\author{
Claudinéia Barboza de AZEVEDO² \\ Claudia Regina Mosca GIROTO ${ }^{3}$ \\ Ana Paula de Oliveira SANTANA ${ }^{4}$
}

\begin{abstract}
RESUMO: o estudo objetivou o mapeamento da produção científica sobre surdez publicada na Revista Brasileira de Educação Especial, desde sua criação, em 1992, até 2013, de maneira a acompanhar a trajetória sobre a forma como a surdez e suas especificidades têm sido retratadas nas produçôes veiculadas nesse periódico. A coleta de dados permitiu a identificação de 49 artigos. Foram considerados, para a análise de dados: distribuição anual dessa produção científica; tipo de autoria; área de formação dos autores; gênero textual empregado; tipo de pesquisas realizadas; temas relacionados a surdez; e abordagens terapêutica/ educacional utilizadas. Os resultados demonstraram uma tendência de crescimento dessa produçáo, nos períodos associados com mudanças na legislação. Prevaleceu a autoria em duplas e Educação, Fonoaudiologia e Psicologia, como principais áreas de formação dos autores. Foram publicados, mais frequentemente, relatos de pesquisas, dos tipos avaliação, intervenção e descrição, seguidos por ensaios e artigos de revisão de literatura. O tema Letramento foi o mais ligado à surdez, e o Bilinguismo figurou como abordagem mais enfatizada. Cabe destacar a importância desse periódico, na divulgação, visibilidade e acessibilidade de artigos publicados sobre surdez, em razão da frequência de tal publicação e da diversidade de temas relacionados a essa área, bem como a necessidade de ampliação de pesquisas que abordem o processo de apropriação da L1 e da L2, náo apenas no que diz respeito à sua instrumentalizaçáo, mas também em relação à natureza das práticas pedagógicas e contextos de uso, em consonância com os perfis linguísticos dos surdos matriculados no ensino regular.
\end{abstract}

PALAVRAS-CHAVE: Educação Especial. Surdez. Revista Brasileira de Educação Especial.

\begin{abstract}
Brazilian Journal of Special Education since its creation in 1992 until 2013, so as to accompany the trajectory of how deafness and its specificities have been portrayed in productions aired this journal. Data collection allowed the identification of 49 articles. We considered for data analysis: annual distribution of this scientific production; type of authorship; author's area of expertise; textual genre; types of research conducted; issues related to deafness; and therapeutic/educational approaches used. The results showed a trend of growth in this production in the periods related to changes in legislation. Double authorship, Education, Speech Therapy and Psychology prevailed as major areas of formation of authors. The most frequent type of publication were: research report, types of assessment, intervention and description; followed by essays and literature reviews. The theme Literacy was the most often related to deafness, and Bilingualism figured as the most emphasized approach. It is worth emphasizing the importance of this journal for disclosure, visibility and accessibility of published articles on deafness, due to the frequency of such publication and the diversity of issues related to this area, as well as the need to expand research that addresses the process of appropriation of L1 and L2, not only with regard to its instrumentalization, but also on the nature of teaching practices and contexts of use, in line with the language profiles of deaf enrolled in general education.
\end{abstract}

KEYWORDS: Special Education. Deafness. Brazilian Journal of Special Education.

${ }^{1}$ http://dx.doi.org/10.1590/S1413-65382115000400010

${ }^{2}$ Colaboradora do Centro de Formação, Extensão e Pesquisa em Inclusão da FFC/UNESP, Campus de Marília, Marília, SP, Brasil. claudineiauli@uol.com.br

${ }^{3}$ Docente do Departamento de Educação Especial do Programa de Pós-Graduação em Educação Escolar da Faculdade de Ciências e Letras - UNESP, Campus de Araraquara, Araraquara, SP, Brasil. claudia.mosca@marilia.unesp.br

${ }^{4}$ Docente do curso de Fonoaudiologia e do Programa de Pós-Graduação em Linguística da Universidade Federal de Santa Catarina, UFSC, Florianópolis, SC, Brasil. anaposantana@hotmail.com 


\section{INTRODUÇÃo}

A Educação Especial, no Brasil, é uma área que vem enfrentando mudanças para se adequar às políticas públicas. Muitos estudos têm acompanhado a trajetória dessa área, a partir do mapeamento da sua produção científica, a exemplo das publicações de Dias et al. (1987), Nunes, Ferreira e Mendes et al. (2003), Omote (2003), Manzini (2003, 2011), Hayashi et al. (2006), Tinós e Castro (2007), Bueno (2008), Nunes, Braun e Walter (2011), dentre outros, os quais indicaram tendências e temas abordados nas produçôes de conhecimento veiculadas sob a forma de artigos, dissertações, teses etc.

Estudos dessa natureza têm permitido o mapeamento bibliográfico da produção científica em determinada área de conhecimento, de maneira a situar, historicamente e/ou contextualmente, tal produção, bem como a identificação de tendências e perspectivas nas áreas investigadas que podem se constituir em importantes indicadores para a ampliação de pesquisas na área especificada (ANDRÉ, 2001; FERREIRA, 2002; BUENO, 2008; NUNES; BRAUN; WALTER, 2011).

$\mathrm{O}$ monitoramento da produção científica, direcionado à apresentação de um panorama nacional, numa determinada área, pode indicar ainda a discrepância das publicações produzidas nessa área em relação a outras áreas afins, a concentração da produção em determinado aspecto de determinada área, em detrimento de outros aspectos que tambem carecem de investigação, o cotejamento da produção nacional e internacional, entre outras questóes (YAMAMOTO et al., 2002; FERREIRA; YOSHIDA, 2004; MUNHOZ et al., 2007).

Seguindo essa tradição de recuperar a história e analisar os caminhos percorridos na pesquisa e divulgação de novos conhecimentos, ganham saliência, no presente estudo, as publicaçóes sobre surdez, divulgadas na Revista Brasileira de Educação Especial (RBEE), uma vez que a surdez tem sido vinculada historicamente à Educação Especial, e esse periódico tem-se constituído num importante veículo de disseminação, visibilidade e acessibilidade da produção científica em tal área.

No censo demográfico do IBGE/2010 (BRASIL, 2010), cerca de 45,6 milhóes de pessoas se declararam com alguma deficiência, no Brasil - 23,9\% da população (190.732.694 pessoas têm algum tipo de deficiência - visual, auditiva, física ou intelectual). Desse total, 7,6\% são surdas, ou seja, 14.495.684. Há um número bastante significativo de pessoas com perdas auditivas de graus e idades variados. Por sua vez, a surdez tem figurado como tema nos mais diversos tipos de publicaçóes relacionadas aos aspectos clínicos, educacionais e sociais. Ademais, as crescentes mudanças na legislação nacional, sob influência de políticas mundiais (KASSAR, 2011), também têm contribuído para que as reflexóes sobre a surdez se consolidem como terreno fértil para o desenvolvimento de estudos nessa área, o que repercute, sem dúvida, nas publicações sobre essa temática. Dessa maneira, o aumento do número de pessoas identificadas com deficiências e a modificação das políticas públicas educacionais têm ocasionado modificaçôes no cenário de pesquisas sobre o tema.

Nos últimos dez anos, as discussões envolveram mudanças significativas nesse cenário, desde as abordagens educacionais e clínicas (Oralismo, Comunicação Total e Bilinguismo), com o desenvolvimento e/ou aperfeiçoamento de novas tecnologias, como próteses auditivas e implantes cocleares, até o surgimento de novos profissionais legitimados para dar conta das es- 
pecificidades da surdez, como o intérprete e o instrutor surdo. Essas modificações vieram igualmente, em grande parte, de mudanças nas políticas públicas educacionais (SANTANA, 2011).

Analisando com mais detalhes as políticas educacionais, verifica-se que a proposta de educação bilíngue ganhou respaldo legal em 2002, quando o governo federal oficializou a Língua Brasileira de Sinais - Libras -, a partir da Lei no 10.436/2002 (BRASIL, 2002). Ressalte-se, porém, que tal lei só foi regulamentada em 2005, por meio do decreto número no 5.626 (BRASIL, 2005), o qual dispôs que os sistemas educacionais federal, estaduais e municipais devem garantir a inclusão da disciplina de Libras nos cursos de Pedagogia, demais licenciaturas e de Fonoaudiologia, dentre outras determinaçóes. Principalmente desde 2002, essas mudanças com relação à área da surdez também ampliaram o interesse de profissionais de áreas afins por esse tema (GIROTO; BERBERIAN; SANTANA, 2014). Frente a esse cenário, cabem alguns questionamentos: de que forma as mudanças contextuais promovem mudanças na produção de conhecimento? Quais formas de produção abordam e/ou revelam essas modificaçóes?

Com base nesse cenário e questionamentos, o presente estudo objetivou o mapeamento da produção científica sobre surdez publicada na RBEE, desde sua criação, em 1992, até 2013, de maneira a acompanhar a trajetória sobre o modo como a surdez e suas especificidades têm sido retratadas nas produçóes veiculadas nesse periódico.

\section{Método}

Para a realização deste estudo, de natureza bibliográfica, a RBEE foi definida como locus para a coleta de dados, por figurar como único periódico, dentre os que representam nacionalmente a Educação Especial, no extrato de A2 a A1, do Sistema WebQualis, da Coordenação de Aperfeiçoamento de Pessoal de Nível Superior (CAPES), o qual se caracteriza como um importante índice de padrão de qualidade editorial. Esse periódico apresenta periodicidade trimestral, sob a responsabilidade da Associação Brasileira de Pesquisadores em Educação Especial (ABPEE), sendo sua impressão realizada em parceria com a Faculdade de Filosofia e Ciências (FFC), da UNESP/Campus de Marília/SP. Objetiva dar suporte ao intercâmbio de informaçóes técnico-científicas em Educação Especial e áreas afins. Possui reconhecimento e abrangência nacional e internacional, encontrando-se bem definida sua missão.

Inicialmente, foi realizada a leitura dos sumários de todos os números da RBEE, publicados no período de 1992 a 2013, os quais se encontram atualmente disponíveis nas páginas da ABPEE e da biblioteca eletrônica SciELO, na internet. Diante da grande variedade de gêneros discursivos que compóem esse periódico científico, ao longo de sua trajetória, foram adotados os critérios propostos por Manzini (2003, p.14), sendo "[...] priorizados os artigos que indicavam algum tipo de produção de conhecimento e desconsiderados os artigos de divulgação”.

Com base nesses critérios, foi efetuada uma nova leitura dos sumários, de forma a identificar os artigos que fizessem algum tipo de referência à surdez. Foram encontrados 49 artigos que satisfizeram as condiçóes estabelecidas, dentre relatos de pesquisa, ensaios e revisóes de literatura, e se tornaram objeto deste estudo. Cabe ressaltar que a expressão surdez é aqui 
compreendida conforme propóe o Decreto 5.626 (BRASIL, 2005), em detrimento da expressão deficiência auditiva, que também figura em parte dos artigos analisados.

A análise empreendida, a partir da leitura, na íntegra, desses artigos, subsidiada pela abordagem qualitativa, permitiu considerar: a distribuição anual dessa produção científica; o tipo de autoria; a área de formação dos autores; o gênero textual empregado; os tipos de pesquisas realizadas; os temas associados à surdez; e as abordagens terapêutica/educacional utilizadas. Esses dados foram corroborados pela análise quantitativa e organizados de sorte a evidenciar a distribuição de sua frequência e as relações entre as variáveis consideradas.

\section{Resultados E discussáo}

Os resultados da análise empreendida são apresentados, a seguir, de acordo com os indicadores considerados.

\subsection{ANO E QUANTIDADE DE ARTIGoS PUblicados}

Conforme indica o Gráfico 1, em 19 anos de publicação da RBEE, foram localizados 49 artigos relacionados à surdez. Nos anos de 1993, 1997 e 1998, a RBEE não foi publicada. Foi possível notar que não houve publicações relacionadas à surdez nos anos de 1992, 1995, 1999 e 2005. No entanto, nos últimos anos, desde 2006, a presença de artigos sobre esse tema passou a ser constante, atingindo seu auge em 2009, quando foram publicados oito artigos.

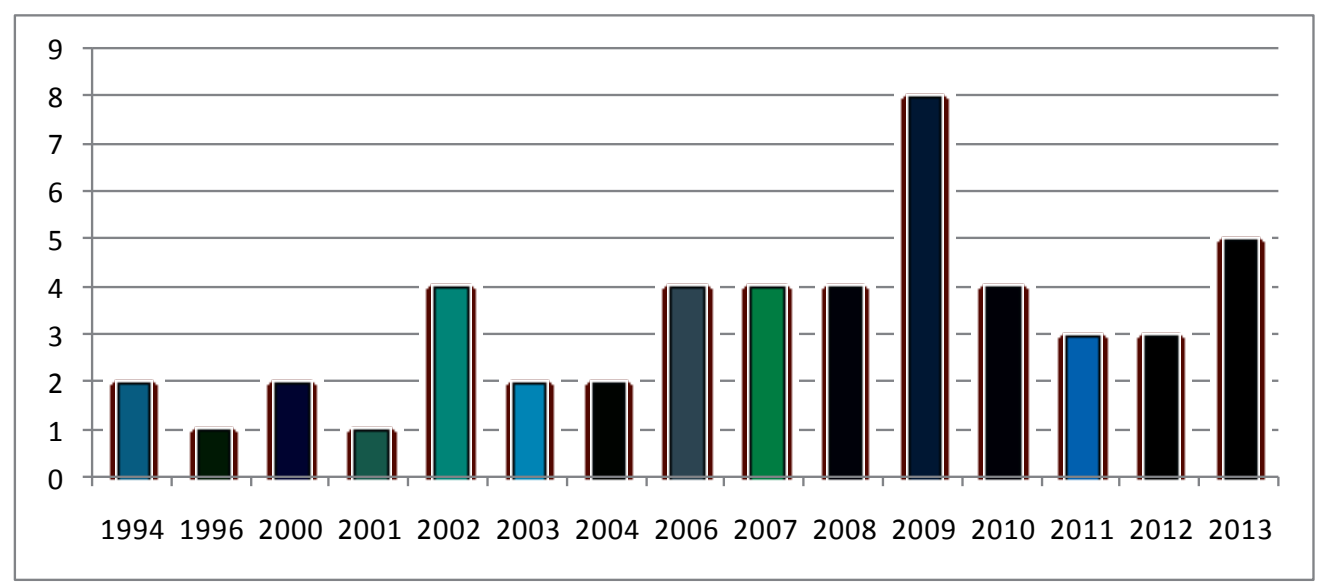

Gráfico 1 - Distribuição dos artigos publicados na RBEE no período de 1994 a 2013.

Fonte: elaboração própria.

O crescimento do número de artigos relacionados à surdez pareceu acompanhar uma tendência que se aplicou também à área da fonoaudiologia, conforme estudo realizado por Munhoz et al. (2007), os quais, ao considerarem o período de 1980 a 2004, constataram um aumento no número de publicaçóes na década de 1990, em decorrência de aspectos contextuais, como a abertura de novos cursos e Instituiçóes de Ensino Superior (IES), principalmente nas regióes Sul e Sudeste do país. 
No caso da RBEE, as mudanças contextuais pareceram ter relação com as modificações provocadas pela legislação e com a sistematização de políticas públicas educacionais, orientadas pela perspectiva da educação inclusiva, uma vez que podem ser apontadas como fatores que impulsionaram os estudos e publicaçóes nessa área, tais como: a Lei 10.436 (BRASIL, 2002), que trata do reconhecimento da Libras como modalidade linguística e língua natural do surdo, com suas regulamentações posteriores; o Decreto 5.626 (BRASIL, 2005); e a Política Nacional da Educação Especial na Perspectiva da Educação Inclusiva (BRASIL, 2007), que conferiu à Educação Especial caráter complementar e/ou suplementar, transversal a todas as modalidades e níveis de ensino, desde a educação infantil até o ensino superior, dentre outras modificaçóes. Como explicitado mais adiante, foi observado um maior número de artigos sobre o bilinguismo, no que se refere às abordagens terapêuticas/educacionais, o que corrobora a influência dessas políticas educacionais na produção científica, na área da surdez (GIROTO; BERBERIAN; SANTANA, 2014).

Outro importante fator, o qual pode ser considerado fundamental para tal crescimento, diz respeito à melhor qualificação obtida pela RBEE, ao longo de sua trajetória, em decorrência da qualidade e abrangência desse periódico, tanto no que se refere ao seu alcance científico quanto aos temas abordados nos textos veiculados.

\subsection{Tipo DE AUTORIA DOS ARTIGOS PUBLICADOS}

A análise da autoria dos artigos relativos à surdez revelou a prevalência de artigos redigidos em coautoria, sendo 40,8\% escritos em duplas, $18,4 \%$ em trios e $24,5 \%$ redigidos por grupos com mais de três coautores, em contraposição a 16,30\%, elaborados individualmente, conforme ilustra o Gráfico 2.

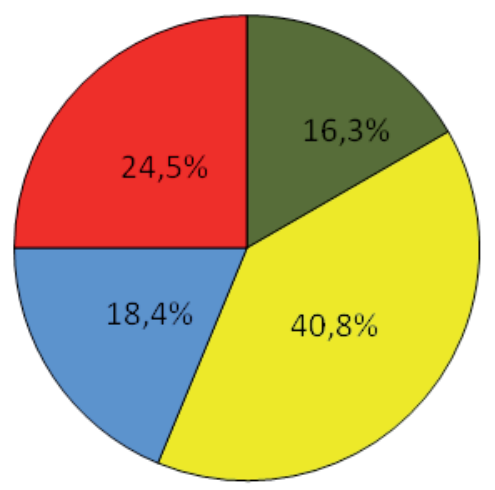

Individual

$\square$ Duplas

Trios

Grupos

Gráfico 2 - Distribuição da autoria de artigos sobre surdez publicados na RBEE de acordo com o tipo de autoria.

Fonte: elaboração própria.

É importante ressaltar o enfoque multidisciplinar nos agrupamentos de autores que, muitas vezes, revelaram diferentes áreas de origem: fonoaudiologia e pedagogia; pedagogia e 
psicologia; linguística e fonoaudiologia, entre outras. As publicaçóes em duplas, em sua grande maioria, compreenderam artigos decorrentes de monografias de especializaçóes, dissertaçóes de mestrado e teses de doutorado, que incluíram o autor e o orientador, em coautoria. Esse dado permitiu inferir o aumento de interesse pelo tema da surdez, retratado nas publicaçóes produzidas em diversos programas de pós-graduação, de diferentes IES do Brasil (NUNES; BRAUN; WALTER, 2011).

\section{3 ÁREAS DE FORMAÇÃO DOS AUTORES E COAUTORES}

Para a análise da área de origem dos autores e coautores dos artigos, foram considerados os vínculos por eles declarados em nota de rodapé, por ocasiấo da publicação dos artigos analisados, exemplificados no Gráfico 3.

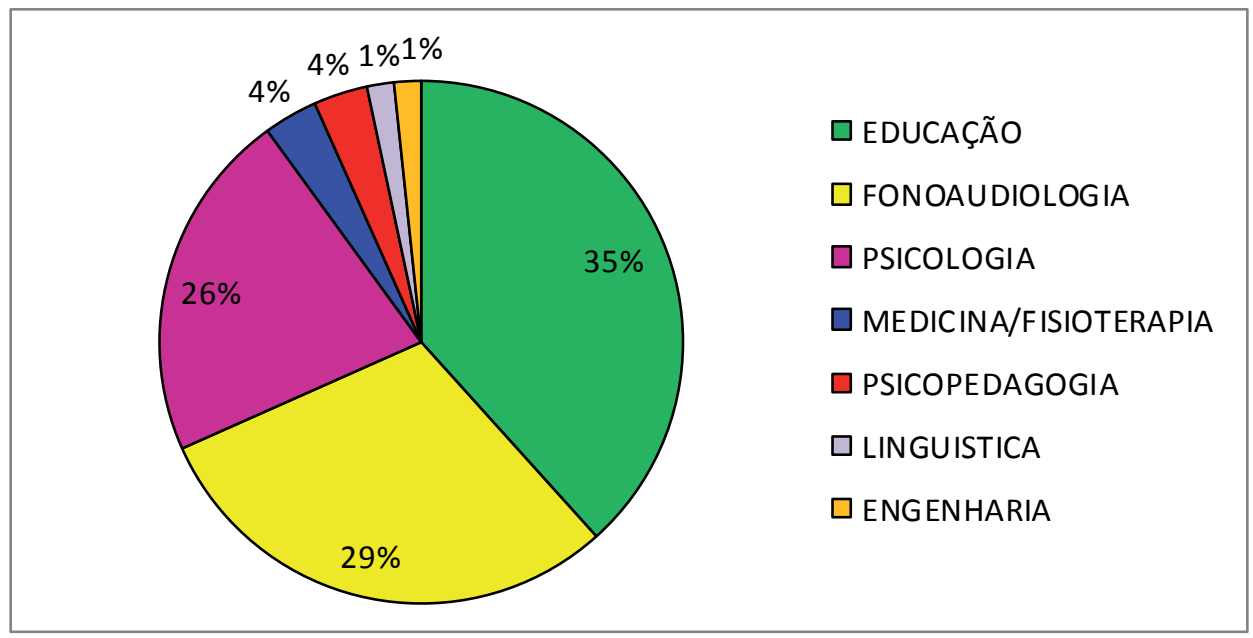

Gráfico 3 - Distribuição dos artigos por área de formação dos autores e coautores.

Fonte: elaboração própria.

O caráter multidisciplinar da RBEE está presente desde sua idealização, na XIII Reunião da Associação Nacional de Pós-Graduação e Pesquisa em Educação (ANPEd), no ano de 1990, quando, segundo Dias et al. (2003), foi observado que as pesquisas em Educação Especial, produzidas em diferentes áreas de conhecimento, ficavam dispersas, pois sua divulgação ocorria apenas nos respectivos canais.

Quanto à manutenção desse caráter multidisciplinar, foram constatadas três áreas básicas de conhecimento, das quais se originaram quase que a totalidade dos artigos: a Educação, a Fonoaudiologia e a Psicologia. Outras áreas que apareceram foram a Medicina/Fisioterapia, a Psicopedagogia, a Linguística e a Engenharia, sendo que estas duas últimas áreas corresponderam a 1\% cada uma, na distribuição dos autores e coautores nas áreas identificadas.

Verifica-se, assim, que os educadores, os fonoaudiólogos e os psicólogos são também os profissionais que estão mais ligados às açóes na área da surdez. Tais profissionais têm sido mencionados, inclusive, em recentes normativas e dispositivos legais, como importantes, dentre 
outros, para a composição de equipes interdisciplinares na Educação Especial e seus respectivos serviços de apoio especializados (BRASIL, 2007, 2011). No que concerne particularmente aos educadores e fonoaudiólogos, esses profissionais devem, ainda, cursar disciplina de Libras nos seus respectivos cursos de graduação (BRASIL, 2005).

\subsection{GÊNERO TEXTUAL dOS ARTIGOS PUBLICADOS}

Em sua trajetória, a RBEE tem publicado artigos que compreendem diferentes gêneros: relato de pesquisa, ensaio, revisão bibliográfica, relato de experiência, depoimentos, resenhas, notícias e reprodução de documentos oficiais. Segundo definido na trajetória metodológica, neste estudo, foram selecionados apenas os artigos cujo gênero representasse produção de conhecimento (MANZINI, 2003). Dessa forma, foram escolhidos os 49 artigos anteriormente mencionados. Quanto ao gênero textual, esses artigos foram, inicialmente, classificados conforme a nomenclatura utilizada pela própria revista.

O Gráfico 4 ilustra a distribuição observada, sendo que, do total de 49 artigos considerados, 43 (88\%), ou seja, a maioria dos artigos selecionados, caracterizaram relatos de pesquisa, tendo sido localizados apenas cinco (10\%) ensaios e uma revisão de literatura (2\%).

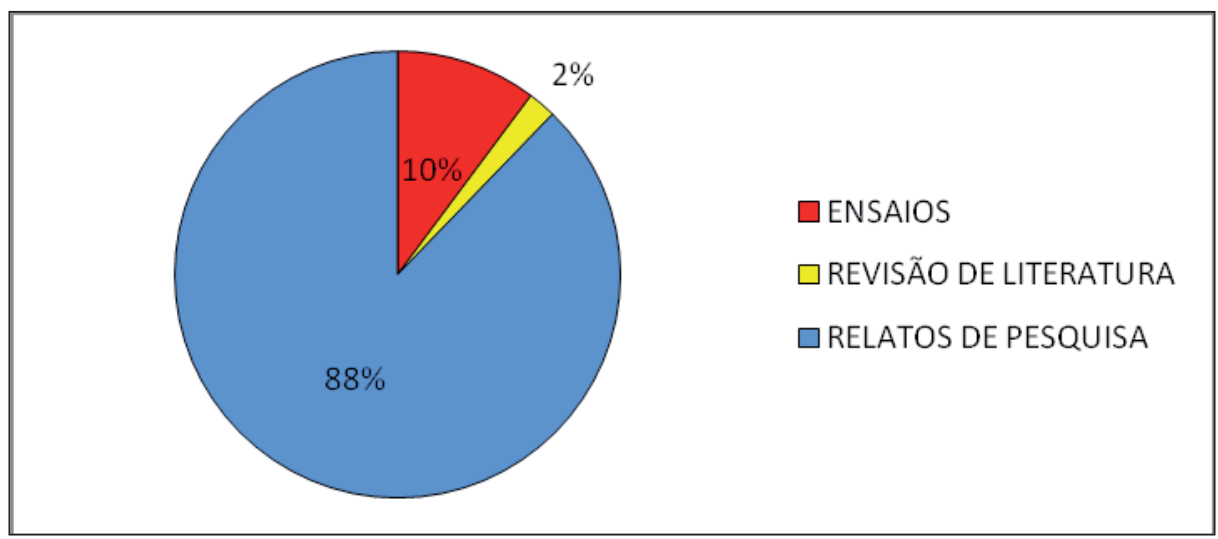

Gráfico 4 - Distribuição dos artigos publicados na RBEE de acordo com o gênero textual. Fonte: elaboração própria.

Quanto a essa prevalência do gênero relato de pesquisa, pode-se inferir que se encontra em consonância com a necessidade de promover o intercâmbio de informaçóes científicas sobre a Educação Especial, que, segundo Dias et al. (2003), constitui um fator determinante do nascimento da revista. Esses relatos, além de se referirem a pesquisas produzidas no âmbito da pós-graduação, tanto lato sensu quanto stricto sensu, como mencionado anteriormente, também, retrataram parte das produçóes de grupos de pesquisas já sedimentados na área.

O ensaio ainda pode ser considerado como um gênero que tem tido pouca produção, o que, obviamente, pode ter relação com as normas estabelecidas pelo periódico, assim como a quantidade de artigos desse gênero encaminhados para publicação. Condição semelhante pode ser observada em relação ao gênero revisão de literatura. 
Cabe ressaltar que, na academia, a produção de ensaio não é uma prática sistemática, diferentemente do que ocorre com os relatos de pesquisa.

\subsection{Tipos DE PESQUISAS REALIZADAS}

No que tange ao gênero relato de pesquisa, após a identificação inicial em conformidade com a classificação proposta pela RBEE e com os critérios previamente estabelecidos, foi possível perceber a importância de delimitar uma nova categorização desse tipo de pesquisa, uma vez que foram observados exemplares de natureza muito diferente.

Dessa maneira, a análise foi direcionada para a classificação desses relatos nos seguintes tipos: intervenção, avaliação e descrição. Os relatos atinentes a pesquisas as quais implicaram em intervenção junto aos sujeitos analisados, mesmo que esta fosse precedida e/ou sucedida por uma avaliação, couberam na categoria intervenção. Os relatos de pesquisas que avaliaram ou apenas analisaram a situação dos sujeitos em determinado contexto ficaram na categoria avaliação. Relatos de natureza mais descritiva, nos quais não foi possível identificar ênfase maior na avaliação ou intervenção ou que se propuseram apenas descrever práticas e/ou métodos de pesquisa, foram encaminhados para a categoria descrição.

Conforme ilustra o Gráfico 5, do total de 43 artigos do tipo relato de pesquisa, 23 $(53,5 \%)$ caracterizaram o tipo avaliação, 12 (28\%) se referiram ao tipo intervenção e oito $(18,5 \%)$ apresentaram perfil pertinente ao tipo descriçáo.

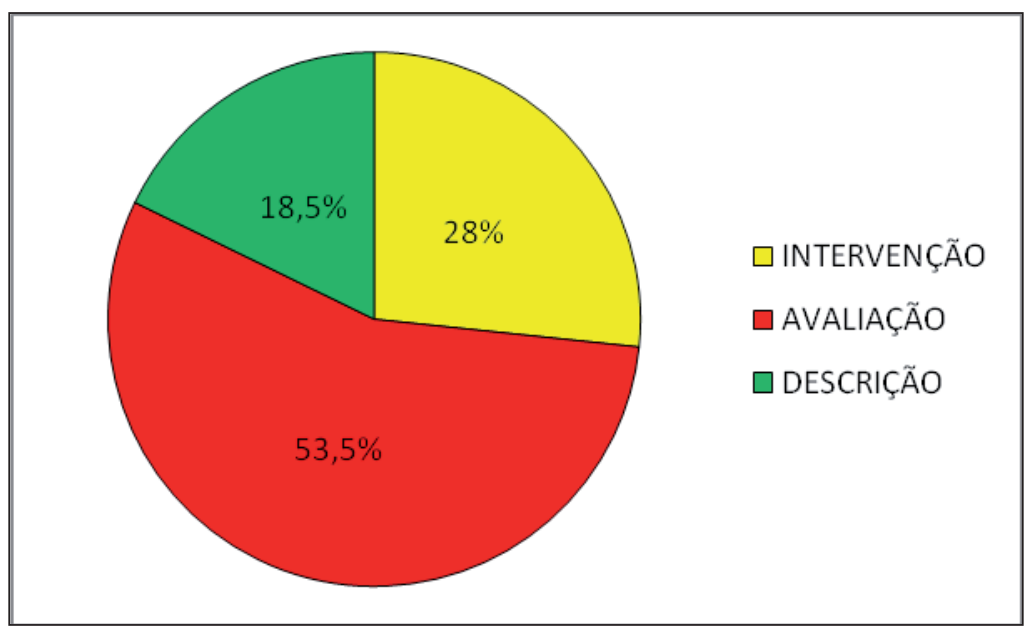

Gráfico 5 - Distribuição dos artigos do gênero relato de pesquisa de acordo com a classificação do tipo de pesquisa realizada.

Fonte: elaboração própria.

Tal categorização demonstrou que foi constante a presença de pesquisas de natureza avaliativa, nos artigos sobre surdez. Os autores evidenciaram o diagnóstico e a eficiência de estratégias e recursos tecnológicos, por meio da análise do conhecimento e do desenvolvimento das pessoas com surdez. Esses dados se justificam por conta do grande número de pesquisas relativas 
a resultados de avaliação, que envolvem entrevistas e resultados de análises das práticas educacionais. Ou seja, propostas de avaliação de diversos aspectos que envolvem o contexto da surdez.

\subsection{TEMAS RELACIONADOS À SURDEZ}

A leitura dos 49 artigos que constituíram a amostra deste estudo permitiu agrupar os temas voltados para a surdez, conforme o predomínio do assunto ou o enfoque adotado em cada artigo. O Gráfico 6 retrata a distribuição da quantidade de artigos por temas identificados.

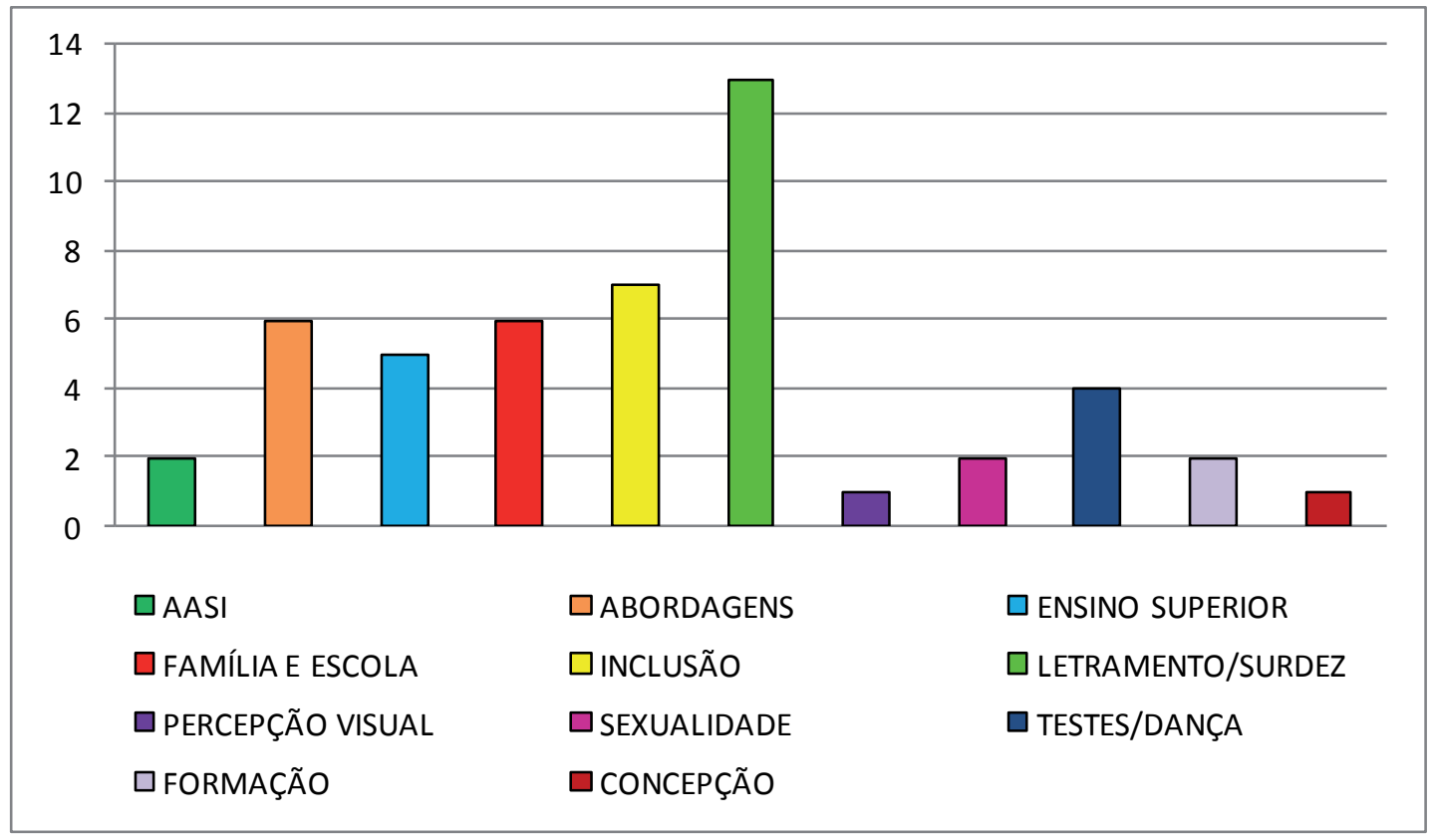

Gráfico 6 - Distribuição dos artigos publicados de acordo com o assunto ou enfoque abordado nos artigos.

Fonte: elaboração própria.

A seguir, são descritas, sucintamente, as características principais de cada um dos temas ligados à surdez, evidenciados na análise empreendida.

Aparelho de Amplificação Sonora Individual (AASI): enfocado em dois relatos de pesquisa referentes ao uso de AASI e às condiçóes de adaptação ao seu uso, bem como à avaliação dos benefícios proporcionados pelo aparelho e sua aceitação por parte de pessoas com surdez (BOSCOLO et al., 2006; ZUGLIANI; MOTTI; CASTANHO, 2007).

Abordagens terapêuticas/educacionais: caracterizado por seis artigos que apresentaram explicaçóes e discussóes acerca das abordagens de exposição à linguagem e a relação com a aprendizagem, na educação de pessoas com surdez (COSTA, 1994; GIANINI; PESSOA; DORZIAT, 1996; CAPOVILLA, 2000; CAPOVILLA; CAPOVILLA, 2002; BATISTA; COSTA, 2003; DE PAULA, 2009). 
Surdez e acesso ao ensino superior: abordado em cinco artigos que trataram da descrição e análise de variados aspectos sobre o acesso de pessoas com surdez ao ensino superior, no Brasil, com enfoque nos aspectos histórico-sociais relacionados às condiçóes proporcionadas pela Lei no 10.436 (BRASIL, 2002), que oficializa a Língua Brasileira de Sinais (Libras) como língua natural das pessoas com surdez, e pelo Decreto no 5.626 (BRASIL, 2005), que a regulamenta (MANENTE; RODRIGUES; PALAMIN, 2007; GUARINELLO et al., 2008; FRANCO, 2009; GUARINELLO et al., 2009; CRUZ; DIAS, 2009).

Papel da familia e escola na inclusão de pessoas com surdez: demonstrado em seis relatos de pesquisa sobre experiências de orientação e capacitação dos pais de crianças com surdez ou surdocegueira e avaliaçóes por eles realizadas, assim como sobre o reconhecimento da importância da família nos processos de inclusão (DIAS et al., 2002; ARAOZ; COSTA, 2008; SCHEMBERG; GUARINELLO; SANTANA, 2009; MOTTI; PARDO, 2010; SCHEMBERG; GUARINELLO; MASSI, 2012; FREITAS; MAGALHAES, 2013).

Inclusão da criança com surdez no ensino regular: presente em sete relatos de pesquisas efetivadas nas redes pública e privada de ensino, sob o ponto de vista dos diferentes participantes envolvidos: professores, colegas de sala e crianças com surdez, com o enfoque no insucesso dos casos analisados (DE PAULA; OLIVEIRA, 2004; GUARINELLO et al., 2006; LACERDA, 2007; RIOS; NOVAES, 2009; ASPILICUETA et al., 2013; RESENDE; LACERDA, 2013; MARQUES; BARROCO; SILVA, 2013).

Letramento e surdez: caracterizado em 13 artigos, com reflexóes sobre os variados aspectos do processo de apropriação do Português escrito como segunda língua (L2), por pessoas com surdez, além da discussão sobre técnicas e avaliaçóes, tendo sido o tema mais recorrente, no total de artigos analisados (GÓES; ANDRADE, 1994; CADER; FÁVERO, 2000; BATISTA et al., 2001; COSTA, 2002; MASINI, 2003; CAPOVILLA et al., 2006; GUARINELLO; BERBERIAN, 2007; PINOTTI; BOSCOLO, 2008; ARAÚJO; LACERDA, 2008; CRATO; CÁRNIO, 2009; DUARTE; BRAZOROTTO, 2009; SOFIATO; REILY, 2012; FLOR; VANZIN; ULBRICHT, 2013).

Percepção visual: destacado em um artigo de revisão de literatura sobre a percepção visual da criança com surdez: "Percepção visual na criança surda: aspectos anátomo-funcionais para profissionais da reabilitação e da Educação Especial” (DELIBERATO; GONÇALVES, 2002).

Sexualidade e surdez: apresentado em dois relatos de pesquisa sobre intervenção e avaliação junto a pessoas com surdez (CURSINO et al., 2006; PINHEIRO FILHO et al., 2010).

Avaliação da surdez e uso de testes e dança: caracterizado em quatro relatos de pesquisa, os quais expuseram e/ou discutiram o uso de testes aplicados ou aplicáveis em pessoas com surdez (KELMAN; BRANCO, 2004; BORGES; LOPES; LOPES, 2010; JACOB; MOLINA; AMORIM, 2010; MONTEZUMA et al., 2011).

Formação de profissionais que trabalham com a surdez: figurado em dois artigos (FARIA, 2011; DORZIAT; ARAÚJO, 2012).

Concepção sobre surdez: apresentado em apenas um artigo (LOPES; LEITE, 2011). 
É interessante observar, na produção identificada, especificidades relativas aos temas, assim como aos movimentos históricos. Por exemplo, poucos trabalhos relacionados às próteses auditivas foram identificados: apenas dois. Possivelmente, esse tipo de tema é mais recorrente em revistas da fonoaudiologia e otorrinolaringologia do que em revistas da educação.

A propósito da inclusão no ensino regular e a relaçáo com a surdez (sete artigos) e, mais especificamente, no que se refere ao acesso de pessoas com surdez ao ensino superior (cinco), foi possível constatar uma produção crescente, o que permite inferir uma maior preocupação com a análise de práticas educativas sob influência das modificações propostas pelas políticas públicas educacionais na perspectiva da educação inclusiva (BRASIL, 2007, 2011).

Outro aspecto relevante que merece destaque diz respeito à relação entre letramento e surdez, retratada numa quantidade maior de artigos (13), tema esse ligado diretamente à educação. Cabe ressaltar, contudo, que a expressão letramento relacionada à surdez começou a ser usada nas produçóes científicas na RBEE, mais sistematicamente, a partir do ano de 2009, possivelmente refletindo as mudanças ocorridas nos estudos nas áreas da linguística e da educação, com o início do emprego dessa expressão (SOARES, 1998; KLEIMAN, 1995) e a adoção desse conceito, nos estudos sobre a surdez.

\subsection{ABORDAGENS TERAPÊUTICAS/EDUCACIONAIS}

Embora nomeiem princípios conceituais diferentes, no campo da linguística aplicada, conforme expóe Borges (2010), muitas vezes os termos abordagem e metodologia são usados como sinônimos, principalmente quando se trata da educação de pessoas com surdez. Neste estudo, fez-se a opção pela utilização da expressão abordagem, em referência à filosofia que orienta os processos de ensino e aprendizagem da linguagem para pessoas com surdez, em dois momentos: primeiro, como um subeixo, pois foram encontrados artigos os quais discorreram especificamente sobre a história e a constituição das abordagens Oralista, Comunicação Total e Bilíngue; segundo, como classificador dos relatos de pesquisa que se referiram ao processo educacional de pessoas com surdez.

Sob esse aspecto, do total de 43 relatos de pesquisas identificados dentre os 49 artigos inicialmente selecionados, foram analisados 37 relatos: três artigos foram desenvolvidos com base na filosofia da Comunicação Total, com destaque para o uso da linguagem de sinais e outros recursos; seis fundamentaram-se no Oralismo, com enfoque no uso da modalidade oral de linguagem; e 28 tiveram como base o Bilinguismo, compreendendo a Libras como primeira língua (L1) e o Português escrito como segunda língua (L2), conforme distribuição mostrada no Gráfico 7. 


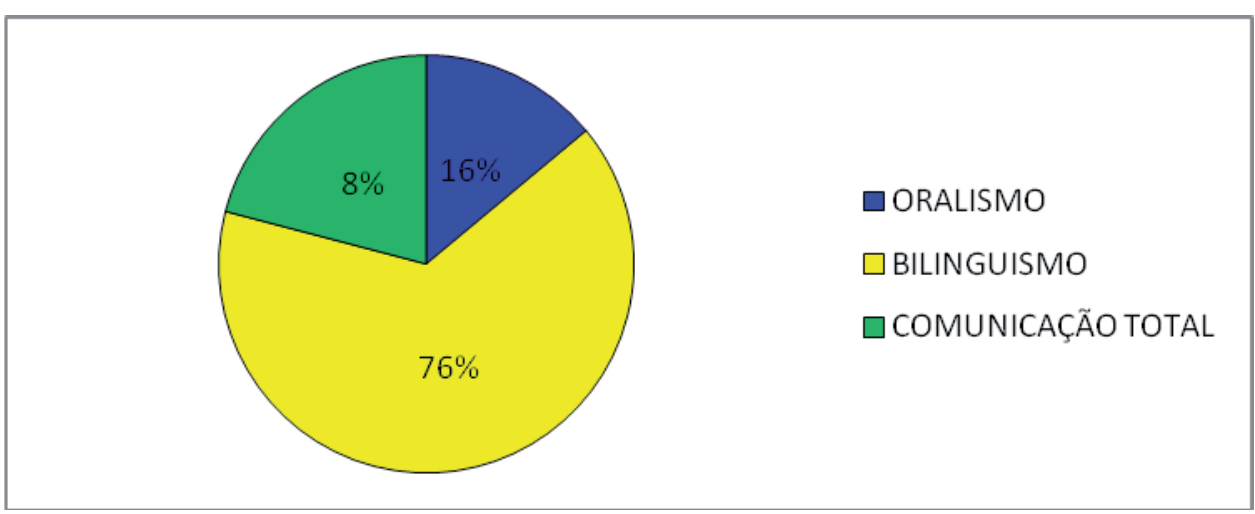

Gráfico 7 - Distribuição dos artigos conforme as abordagens de exposição à linguagem e a relação com a aprendizagem na educação de pessoas com surdez.

Fonte: própria dos autores.

Ao se investigar as relações entre essas abordagens e outros elementos, como a área de origem dos autores ou o ano de publicação das pesquisas, foi possível observar que, do total de relatos de pesquisa concernentes à abordagem oralista, cinco foram produzidos por autores com formação em fonoaudiologia e tiveram como participantes usuários de AASI ou implante coclear, em fase de reabilitação. Quatro destes foram publicados entre 2009 e 2010, o que pode indicar que os avanços tecnológicos na reabilitação implicaram o aumento das pesquisas de avaliação e intervenção junto às pessoas com surdez, usuárias desses recursos. Um único artigo referente a essa abordagem partiu da área da psicologia, constituindo-se numa avaliação da motivação social nas interaçóes escolares de crianças com surdez, além de salientar a adoção da Libras e propor a ideia de que a inclusão dessas crianças junto às ouvintes não representa ganhos para seu desenvolvimento.

Dos três relatos de pesquisas embasados na comunicação total, dois foram publicados por autores e coautores com formação em Psicopedagogia e um da Pedagogia. Neste último, foi exposta uma avaliação dos resultados do uso da comunicação total para a apropriação da linguagem escrita por crianças com surdez, cuja conclusão enfatizou que tal abordagem atrapalha o processo de alfabetização dos surdos em língua portuguesa, pois estes não a distinguem da Libras.

Grande parte dos relatos de pesquisa seguiu a orientação teórica do Bilinguismo, o que compreendeu 28 relatos distribuídos em todos os anos, todos os tipos de pesquisa e todas as áreas. Os relatos anteriores à Lei no 10.436 (BRASIL, 2002) apontaram a necessidade de reconhecer a língua de sinais como o melhor caminho para o desenvolvimento da educação dos surdos. Por sua vez, relatos de pesquisas publicados posteriormente só foram possíveis de realização graças a tal legislação, como, por exemplo, os que apresentaram análises do desempenho de intérprete de Libras no ensino superior. A maior parte dos participantes dessas pesquisas compreendeu usuários de Libras. 


\section{Conclusóes}

O mapeamento dos artigos sobre surdez presentes na RBEE, desde sua criação, em 1992, até 2013, realizado no presente estudo, permitiu concluir que essa temática foi recorrentemente contemplada em suas publicaçóes, considerando que se caracteriza por um periódico científico cujo objetivo é divulgar as pesquisas em Educação Especial, em geral. Além disso, foi possível concluir que, ao longo do período considerado, houve uma tendência de crescimento ascendente da publicação de artigos sobre essa temática, uma vez que, na sociedade brasileira, por conta da legislação que assegurou direitos e mudanças sociais, educacionais, tecnológicas, entre outras, às pessoas com surdez, de movimentos sociais dos quais participam essas pessoas; da criação e regulamentação de profissóes atreladas aos ajustes necessários para a inclusão dos surdos em diferentes contextos, a exemplo da sistematização da profissão de intérprete de língua de sinais e contratação desse profissional para auxiliar surdos matriculados no ensino regular, entre outros aspectos, têm surgido novas possibilidades para fomentar a discussão sobre a surdez, tendo sido retomada a polêmica sobre os diferentes modelos educacionais para a escolarização de surdos.

As análises acerca dos temas, das áreas e dos tipos de autoria dos artigos analisados confirmaram a vocação multidisciplinar dos estudos relativos à surdez. A quantificação dos temas revelou que a preocupaçáo com o acesso ao currículo, por meio da escrita, tem sido uma constante, havendo muitas pesquisas no sentido de diagnosticar as dificuldades das pessoas com surdez, no âmbito educacional.

A classificação das abordagens linguístico-metodológicas que guiam os trabalhos na área demonstrou que, no meio científico, cada abordagem ocupou um lugar determinado pelas condições específicas de cada participante com surdez. O Oralismo foi relacionado aos implantados e usuários de AASI com ganhos significativos. O Bilinguismo, evidenciado como abordagem para pessoas com surdez usuárias de Libras. A Comunicação Total destacou-se como um marco na transição histórica entre as abordagens anteriormente mencionadas, obviamente sem deixar de considerar as implicaçóes sócio-históricas as quais determinaram o prestígio de uma ou de outra, em determinada época.

Em relação às contribuições da RBEE à área da surdez, cabe destacar sua importância na divulgação, visibilidade e acessibilidade a artigos publicados nessa área, em razão da frequência de tal publicação e da diversidade de temas a ela associados. Em acréscimo, o resgate da história das abordagens linguístico-metodológicas e das discussóes fundamentais sobre a educação das pessoas com surdez apontou a necessidade de ampliação de pesquisas que abordem a utilização de práticas pedagógicas no processo de apropriação da L1 e da L2, não apenas no que diz respeito à sua instrumentalização/avaliação, mas também no que se refere à reflexão acerca da natureza dessas práticas e seus contextos de uso, em consonância com a diversidade de perfis linguísticos das pessoas com surdez, matriculadas no ensino regular, bem como retratem experiências de sucesso de inclusão educacional desses surdos em diferentes modelos educacionais. 


\section{REFERÊNCIAS}

ANDRÉ, M. Pesquisa em educação: buscando rigor e qualidade. Cadernos de Pesquisa, São Paulo, n.113, p.51-64, 2001. Disponível em: <http://www.scielo.br/pdf/cp/n113/a03n113>. Acesso em: 02 fev. 2013.

ARAOZ, S. M. M.; COSTA, M. P. R. Aspectos biopsicossociais na surdo-cegueira. Revista Brasileira de Educação Especial, Marília, v.14, n.1, p.21-34, 2008.

ARAÚJO, C. C. M.; LACERDA, C. B. F. Esferas de atividade simbólica e a construção de conhecimento pela criança surda. Revista Brasileira de Educação Especial, Marília, v.14, n.3, p.427-446, 2008.

ASPILICUETA, P. et al. A questão linguística na inclusão escolar de alunos surdos: ambiente regular inclusivo versus ambiente exclusivamente ouvinte. Revista Brasileira de Educação Especial, Marília, v.19, n.3, p.395-410, 2013.

BATISTA, A. S. et al. Consciência fonológica: avaliação e intervenção dos distúrbios de escrita em crianças surdas. Revista Brasileira de Educação Especial, Marília, v.7, n. 2, p.39-51, 2001.

BATISTA, A. S.; COSTA, M. P. R. Abordagens comunicativas e os impasses na construção da escrita do português por crianças surdas. Revista Brasileira de Educação Especial, Marília, v.9, n.2, p.155-162, 2003.

BORGES, E. F. V. Metodologia, abordagem e pedagogias de ensino de língua(s). Linguagem \& Ensino, Pelotas, v.13, n.2, p.397-414, 2010.

BORGES; C. F.; LOPES, R. F. F.; LOPES, J. Estudo das habilidades de memória e raciocínio simbólico e não-simbólico de crianças e adolescentes surdas por meio da bateria padrão do Universal Nonverbal Intelligence Test. Revista Brasileira de Educação Especial, Marília, v.16, n.1, p.83-94, 2010.

BOSCOLO, C. C. et al. Avaliação dos benefícios proporcionados pelo AASI em crianças e jovens da faixa etária de 7 a 14 anos. Revista Brasileira de Educação Especial, Marília, v.12, n. 2, p.255-268, 2006.

BRASIL. Decreto 5.626, de 22 de dezembro de 2005, que regulamenta a Lei no. 10.436, de 24 de abril de 2002, que dispóe sobre a Língua Brasileira de Sinais - Libras e o art. 18 da Lei no 10.098, de 19 de dezembro de 2000. Disponível em: <http://www.planalto.gov.br/ccivil_03/_ato2004-2006/2005/ decreto/d5626.htm>. Acesso em: 13 ago. 2013.

BRASIL. Decreto 7.611/2011, de 17 de novembro de 2011, que dispóe sobre a educação especial, o atendimento educacional especializado e dá outras providências. Disponível em: <http://www.planalto. gov.br/ccivil_03/_Ato2011-2014/2011/Decreto/D7611.htm>. Acesso em: 19 jul. 2011.

BRASIL. Lei no 10.436, de 24 de abril de 2002, que dispóe sobre a Língua Brasileira de Sinais - Libras e da outras providências. Disponível em: <http://www.planalto.gov.br/ccivil_03/leis/2002/110436. htm>. Acesso em: 20 maio 2013.

BRASIL. Ministério do Planejamento, Orçamento e Gestão. Instituto Brasileiro de Geografia e Estatística-IBGE. Censo demográfico 2010. Características gerais da população, religião e pessoa com deficiência, Rio de Janeiro, 2010. Disponível em: <http://www.portaldeacessibilidade.rs.gov.br/http:// deficientefisico.com/resultados-do-censo-2010-feito-pelo-ibge-sobre-pessoas-com-deficiencia $>$. Acesso em: 13 ago. 2013.

BRASIL. Política nacional da educação especial na perspectiva da educação inclusiva. Brasília, DF, 2007. Disponível em: <http://peei.mec.gov.br/arquivos/politica_nacional_educacao_especial.pdf >. Acesso em: 25 maio 2013. 
BUENO, J. G. S. A produção acadêmica sobre inclusão escolar e educação inclusiva. In: MENDES, E. G.; ALMEIDA, M. A.; HAYASHI, M. C. P. I. (Org.). Temas em educaçâo especial: conhecimentos para fundamentar a prática. Araraquara: Junqueira \& Marin; Brasília, DF: CAPES-PROESP, 2008. p.31-47.

CADER, F. A. A. A.; FÁVERO, M. H. A mediação semiótica no processo de alfabetização de surdos. Revista Brasileira de Educação Especial, Marília, v.6, n.1, p.117-131, 2000.

CAPOVILLA, F. C. et al. Quando alunos surdos escolhem palavras escritas para nomear figuras: paralexias ortográficas, semânticas e quirêmicas. Revista Brasileira de Educação Especial, Marília, v.12, n.2, p.203-220, 2006.

CAPOVILLA, F. C. Filosofias educacionais em relação ao surdo do Oralismo à comunicação total e ao bilinguismo. Revista Brasileira de Educação Especial, Marília, v.6, n.1, p.99-116, 2000.

CAPOVILLA, F. C.; CAPOVILLA, A. G. S. Educação da criança surda: o bilinguismo e o desafio da descontinuidade entre a língua de sinais e a escrita alfabética. Revista Brasileira de Educação Especial, Marília, v.8, n.2, p.127-156, 2002.

COSTA, D. A. F. Um novo olhar sobre a singularidade: compreendendo a gênese da escrita de aprendizes surdos. Revista Brasileira de Educaçâo Especial, Marília, v.8, n.1, 2002.

COSTA, M. P. R. Orientaçóes para ensinar o deficiente auditivo a se comunicar. Revista Brasileira de Educação Especial, Marília, v.2, n.1, p.93-106, 1994.

CRATO, A. N.; CÁRNIO, S. M. Análise da flexão verbal de tempo na escrita de surdos sinalizadores. Revista Brasileira de Educação Especial, Marília, v.15, n.2, p.233-250, 2009.

CRUZ, J. I. G.; DIAS, T. R. S. Trajetória escolar do surdo no ensino superior: condiçóes e possibilidades. Revista Brasileira de Educação Especial, Marília, v.15, n.1, p.65-80, 2009.

CURSINO, H. M. et al. Orientação sexual para jovens adultos com deficiência auditiva. Revista Brasileira de Educação Especial, Marília, v.12, n.1, p.29-48, 2006.

DE PAULA, L. S. B. Cultura escolar, cultura surda e construção de identidades na escola. Revista Brasileira de Educação Especial, Marília, v.15, n.3, p.407-416, 2009.

DE PAULA, L. S. B.; OLIVEIRA, M. C. S. L. A motivaçâo social nas interaçôes escolares e o desenvolvimento de crianças surdas. Revista Brasileira de Educação Especial, Marília, v.10, n.2, p.183198, 2004.

DELIBERATO, D.; GONÇALVES, V. M. G. Percepção visual na criança surda: aspectos anátomofuncionais para profissionais da reabilitação e da Educação Especial. Revista Brasileira de Educação Especial, Marília, v.8, n.1, p.109, 2002.

DIAS, T. et al. Caracterização da produção científica do Programa de Mestrado em Educação Especial: dissertaçôes de mestrado. In: CICLO DE ESTUDOS SOBRE DEFICIÊNCIA MENTAL, 4., 1987, São Carlos. Anais...São Carlos, 1987.

DIAS, T. et al. A visão de profissionais multiplicadores em um programa de capacitação com enfoque bilíngue. Revista Brasileira de Educação Especial, Marília, v.10, n.2, p.183-198, 2002.

DIAS, T. R. S. et al. Porque uma revista de Educação Especial: o início. Revista Brasileira de Educação Especial, Marília, v.9, n.1, p.1-15, 2003. 
DORZIAT, A.; ARAUJO, J. R. O intérprete de língua de sinais no contexto da educação inclusiva: o pronunciado e o executado. Revista Brasileira de Educaçáo Especial, Marília, v.18, n.3, p. 391410, 2012.

DUARTE, J. L.; BRAZOROTTO, J. S. Análise das estratégias utilizadas em um grupo terapêutico pedagógico para auxiliar o desenvolvimento da linguagem escrita em crianças com deficiência auditiva. Revista Brasileira de Educação Especial, Marília, v.15, n.3, p.471-484, 2009.

FARIA, J. G. Formação, profissionalização e valorização do professor surdo: reflexôes a partir do Decreto 5.625/2005. Revista Brasileira de Educação Especial, Marília, v.17, n.1, p.87-100, 2011.

FERREIRA, N. S. A. As pesquisas denominadas "estado da arte". Educação e Sociedade, Campinas, v.33, n.79, p.257-272, 2002. Disponível em: <http://www.scielo.br/pdf/es/v23n79/10857.pdf>. Acesso em: 02 fev. 2013.

FERREIRA, S. N.; YOSHIDA, E. M. P. Produção científica sobre psicoterapias breves no Brasil e demais países latino-americanos (1990-2000). Estudos de Psicologia, v.9, n.3, p.523-531, 2004.

FLOR, C. S.; VANZIN, T.; ULBRICHT, V. Recomendaçóes da WCAG 2.0 (2008) e a acessibilidade de surdos em conteúdos da Web. Revista Brasileira de Educação Especial, Marília, v.19, n.2, p.161-168, 2013.

FRANCO, M. Educação superior bilíngue para surdos: o sentido da política inclusiva como espaço da liberdade: primeiras aproximações. Revista Brasileira de Educação Especial, Marília, v.15, n.1, p.15-30, 2009.

FREITAS, H. R. M.; MAGALHAES, C. M. C. Metas e estratégias de socialização que mães de crianças surdas valorizam para seus filhos. Revista Brasileira de Educação Especial, Marília, v.19, n.4, p.545-561, 2013.

GIANINI, E.; PESSOA, D. C. C.; DORZIAT, A. Proposta alternativa para o ensino de surdos: experiência institucional no estado da Paraíba. Revista Brasileira de Educação Especial, Marília, v.4, p.73-78, 1996.

GIROTO, C. R. M.; BERBERIAN, A. P.; SANTANA, A. P. O. Salud, Educación y Educación Especial: principios y paradigmas guías de las prácticas en salud en el contexto educativo inclusivo. In: GIROTO, C. R. M. et al. (Org.). Servicios de apoyo en Educación Especial: una mirada desde diferentes realidades. Alcalá de Henares/Espanha: Servicio de Publicaciones de la Universidad de Alcalá de Henares, 2014. p.115-138.

GÓES, M. C. R.; ANDRADE, S. M. A. R. Consideraçôes sobre a reflexividade de alunos surdos frente à linguagem escrita. Revista Brasileira de Educação Especial, Marília, v.2, n.1, p.7-16, 1994.

GUARINELLO, A. C. et al. A inserção do aluno surdo no ensino regular: visão de um grupo de professores do estado do Paraná. Revista Brasileira de Educação Especial, Marília, v.12, n.3, p.317-330, 2006.

GUARINELLO, A. C. et al. Surdez e letramento: pesquisa com surdos universitários de Curitiba e Florianópolis. Revista Brasileira de Educação Especial, Marília, v.15, n.1, p.99-120, 2009.

GUARINELLO, A. C. et al. O intérprete universitário da Língua Brasileira de Sinais na cidade de Curitiba. Revista Brasileira de Educação Especial, Marília, v.14, n.1, p.63-74, 2008.

GUARINELLO, A. C.; MASSI, G.; BERBERIAN, A. P. Surdez e linguagem escrita: um estudo de caso. Revista Brasileira de Educação Especial, Marília, v.13, n.2, p.205-218, 2007.

HAYASHI M. C. P. I. et. al. Avaliação de aspectos formais em quatro periódicos científicos na área de Educação Especial. Revista Brasileira de Educação Especial, Marília, v.12, n.3, p.369-392, 2006. 
JACOB, R. T. S.; MOLINA, S. V.; AMORIM, R. B. FM Listening Evaluation for Children: adaptação para a língua portuguesa. Revista Brasileira de Educaçáo Especial, Marília, v.16, n.3, p.359$374,2010$.

KASSAR, M. C. M. Percursos da constituição de uma política brasileira de educação especial inclusiva. Revista Brasileira de Educação Especial, v.17, no.spel, p.41-58, 2011.

KELMAN, C. A.; BRANCO, A. U. Análise microgenética em pesquisa com alunos surdos. Revista Brasileira de Educação Especial, Marília, v.10, n.1, p.93-106, 2004.

KLEIMAN, A. Os significados do letramento. Campinas: Mercado de Letras, 1995.

LACERDA, C. B. F. O que dizem/sentem alunos participantes de uma experiência de inclusão escolar com aluno surdo. Revista Brasileira de Educação Especial, Marília, v.13, n.2, p.257-280, 2007.

LOPES, M. A. C.; LEITE, L. P. Concepçôes de surdez: a visão do surdo que se comunica em Língua de Sinais. Revista Brasileira de Educação Especial, Marília, v.17, n.2, p.305-320, 2011.

MANENTE, M. V.; RODRIGUES, O. M. P. R.; PALAMIN, M. A. G. Deficientes auditivos e escolaridade: fatores diferenciais que possibilitam o acesso ao ensino superior. Revista Brasileira de Educação Especial, Marília, v.13, n.1, p.27-42, 2007.

MANZINI, E. J. Análise de artigos da Revista Brasileira de Educação Especial (1992 - 2002). Revista Brasileira de Educação Especial, Marília, v.9, n.1, p.13-23, 2003.

MANZINI, E. J. Tipo de conhecimento sobre a inclusão produzido pelas pesquisas. Revista Brasileira de Educação Especial, Marília, v.17, n.1, p.53-70, 2011.

MARQUES, H. C. R; BARROCO, S. M. S.; SILVA, T. S. A. O ensino da língua Brasileira de sinais na educação infantil para crianças ouvintes e surdas: consideraçóes com base na psicologia históricocultural. Revista Brasileira de Educação Especial, Marília, v.19, n.4, p.503-518, 2013.

MASINI, E. F. S. Aprendizagem totalizante: propicia o aprender de crianças com deficiência visual, de crianças surdas e de crianças sem deficiências sensoriais? Revista Brasileira de Educação Especial, Marília, v.9, n.2, p.237-248, 2003.

MONTEZUMA, M. V. R. et al. Adolescentes com deficiência auditiva: a aprendizagem da dança e a coordenação motora. Revista Brasileira de Educação Especial, Marília, v.17, n.2, p.321-334, 2011.

MOTTI, T. F. G.; PARDO, M. B. L. Intervençâo com pais de crianças deficientes auditivas: elaboração e avaliação de um programa de orientação não presencial. Revista Brasileira de Educação Especial, Marília, v.16, n.3, p.447-462, 2010.

MUNHOZ, C. M. A. et al. Analysis of the speech and language national scientific production on written language. Pró-Fono Revista de Atualização Científica, Barueri, v.19, n.3, p.249-258, 2007.

NUNES, L. R. O. P.; BRAUN, P.; WALTER, C. C. F. Procedimentos e recursos de ensino para o aluno com deficiência: o que tem sido disseminado nos trabalhos do GT 15 da ANPED sobre estes temas? Revista Brasileira de Educação Especial, Marília, v.17, ed.spel, p.23-40, 2011.

NUNES, L. R. O. P.; FERREIRA, J. R.; MENDES, E. G. Teses e dissertaçôes sobre Educação Especial: os temas investigados. In: MARQUEZINE, M.C; ALMEIDA, M.A. (Org.). Colóquios sobre pesquisa em Educação Especial. Londrina: Eduel, 2003. p.113-136.

OMOTE, S. Algumas tendências (ou modismos?) recentes em Educação Especial e a Revista Brasileira de Educação Especial. Revista Brasileira de Educação Especial, Marília, v.9, n.1, p.25-38, 2003. 
PINHEIRO FILHO, T. R. C. et al. Análise do conhecimento sobre DSTS e planejamento familiar entre deficientes auditivos e ouvintes de uma escola pública de Fortaleza. Revista Brasileira de Educação Especial, Marília, v.16, n.1, p.137-150, 2010.

PINOTTI, K. J.; BOSCOLO, C. C. A dramatização como estratégia de aprendizagem da linguagem escrita para o deficiente auditivo. Revista Brasileira de Educação Especial, Marília, v.14, n.1, p.121-140, 2008.

RESENDE, A. A. C.; LACERDA, C. B. F. Mapeamento de alunos surdos matriculados na rede de ensino pública de um município de médio porte do estado de São Paulo: dissonâncias. Revista Brasileira de Educação Especial, Marília, v.19, n.3, p.411-424, 2013.

RIOS, M. V. F.; NOVAES, B. C. A. C. O processo de inclusão de crianças com deficiência auditiva na escola regular: vivências de professores. Revista Brasileira de Educação Especial, Marília, v.15, n.1, p.8198, 2009.

SANTANA, A. P. Linguagem e surdez. São Paulo: Plexus, 2011.

SCHEMBERG, S.; GUARINELLO, A.C.; MASSI, G. O ponto de vista de pais e professores a respeito das interaçóes linguísticas de crianças surdas. Revista Brasileira de Educação Especial, Marília, v.18, n.1, p.17-32, 2012.

SCHEMBERG; S.; GUARINELLO, A. C.; SANTANA, A. P. O. As práticas de letramento na escola e na família no contexto da surdez: reflexôes a partir do discurso dos pais e professores. Revista Brasileira de Educação Especial, Marília, v.15, n.2, p.251-268, 2009.

SOARES, M. Letramento: um tema em três gêneros. Belo Horizonte: Autêntica, 1998.

SOFIATO, C. G.; REILY, L. Justaposiçóes: o primeiro dicionário brasileiro de língua de sinais e a obra francesa que serviu de matriz. Revista Brasileira de Educação Especial, Marília, v.18, n.4, p.553568, 2012.

TINÓS, L. M. S.; CASTRO, S. F. Cadernos de Educação Especial da Revista Educação Especial: uma análise dos últimos 5 anos (2002 - 2006). Revista Educaçâo Especial, n.30, 2007. Disponível em: <http://coralx.ufsm.br/revce/index.htm>. Acesso em: 15 maio 2013.

YAMAMOTO, O. H. et al. Avaliação de periódicos científicos brasileiros na área da psicologia. Ci. Inf, Brasília, DF, v.31, n.2, p.167-177, 2002.

ZUGLIANI, A. P.; MOTTI, T. F. G.; CASTANHO, R. M. O autoconceito do adolescente deficiente auditivo e sua relação com o uso do aparelho de amplificação sonora individual. Revista Brasileira de Educação Especial, Marília, v.13, n.1, p.95-110, 2007.

Recebido em: 23/08/2014

Reformulado em: 10/09/2015

Aprovado em: 15/09/2015 